\title{
Internet use: Perceptions and experiences of visually impaired older adults
}

\section{Patrick Okonji}

Health, Community and Education Studies

University of Northumbria, Newcastle, UK

\section{Monique Lhussier}

Health, Community and Education Studies

University of Northumbria, Newcastle, UK

\section{Catherine Bailey}

Public Health and Wellbeing

University of Northumbria, Newcastle, UK

\section{Mima Cattan}

Public Health and Wellbeing

University of Northumbria, Newcastle, UK

Abstract
Many older people are increasingly using the internet. This study investigated the
experiences of visually impaired older people on internet use and explored how it fits
into their lives. 20 visually impaired older people aged 60 years and over were
recruited from a voluntary organisation for blind people. Qualitative interviews were
conducted with all participants to investigate how they perceive the relevance of
internet use to their daily lives. Findings suggest that the internet not only has


potential to promote their ability to perform daily tasks, cope with vision impairment and feel socially included. However, the rapid pace of technological advancement is feared as a development that could further widen the digital divide if they are not carried along by addressing barriers to their internet.

Keywords: Vision impaired, Information and Communication Technology, internet, older adults, digital divide, computer-based technologies, digital inclusion

\section{Introduction}

In the same vein as global population ageing and vision impairment, the number of older adult users of the internet is increasing (Madden, 2010). Many older adults now rely on the internet to help manage their daily communication, access social care services and gain social involvement (Cook et al., 2010). Although technological advances in computer software and digital assistive technologies have enhanced access to the internet for visually impaired older people, their adoption of the internet is less than their sighted peers (RNIB, 2013). Paucity of research on use of Information and Communication Technology (ICT) by older people with vision impairment has made it more difficult to tackle the digital divide (Hollier, 2007; Kane, 2011). This study explores the perceptions and experiences of visually impaired older people on how computer use fits into their daily lives. By understanding how the internet is utilised by visually impaired older people, knowledge gathered may contribute to more effectively addressing their perception on digital inclusion.

\section{Background}

The term "vision impairment" describes a range of conditions affecting visual acuity (clarity of vision) and visual field; and leading to irreversible loss of vision. Many studies have shown that the internet has the potential to enhance communication and daily tasks for people living with disabilities. Bishop, Taylor and Froy (2000) investigated the potential of Computer Mediated Communication (CMC) to relieve social isolation among a sample of participants with hearing impairment. The study found that it was easier for participants to communicate online than face-to-face contexts. Swindell (2002) reported that communication technologies have potential to minimize social isolation and thereby improve quality of life. Online social and 
emotional support from family and friends have been linked to lower stress, better adaptation and having a sense of belonging (Hageboom, McDermott,Perrin, Osman, \& Bell-Ellison, 2010; Russell, Cambell, \& Huges, 2009; Sum, Mark, Pourghason, \& Huges, 2009). Egan, Chenoweth and McAuliffe (2006) found that email enabled participants to compensate for challenges posed by impairments that affected information processing, response formulation, concentration and recall. Many other studies suggest that older people can connect to people who are having similar experiences and receive practical help in adjusting to life with disability (Eysenbach, 2008; Sayago \& Blat, 2010; Sayago, Sloan, \& Blat, 2013). However, despite these benefits, not all older people use computers. Evidence suggests that older people with disabilities such as vision impairment are much less likely to use the internet due to the myriad of challenges hindering their access (Gerber \& Corinne, 2001; Hollier, 2007; Kane, 2011; RNIB, 2013).

As computers are increasingly becoming integral to modern living, it is very important that older people learn how to adapt to new computer-based technologies in order to be part of the current information society (European Commission, 2007). In recent years, many technologies are operated through computer systems as seen in smart phones, Automatic Teller Machines (ATMs), ticket machines, hospital check-in services, etc. Operating these technologies require an understanding of their underlying systems of operation; that of networked digital devices, the internet and the World Wide Web.

Research suggests that many older people have never used the internet (Niehaves \& Plattfault, 2014; Office of National Statistics, 2013). According to a recent report by Age UK (2013), older people aged 60 and over in the North of England are less likely to be online compared to those in the South. The report suggests that only $28 \%$ of older people in Tyne and Wear use the internet. This contrasted sharply with their peers in Surrey, where $63 \%$ of older adults reported using the internet. In other Southern parts of the country (such as Bedfordshire, Suffolk, Oxfordshire, Buckinghamshire), not less than $50 \%$ of older people aged 65 and over use the internet. The Age UK (2013) report raised concerns over the NorthSouth divide and highlighted the need for the government, local authorities and private organisations to help older adults get online.

Many studies have investigated the reasons for the low internet adoption among older people. Specific factors which have been identified as affecting 
adoption decisions for older people include socio-economic barriers such as income, cost of computers and educational level (Eastman \& lyer, 2004; Juznic, Blazic, Mercun, \& Plestenjak, 2006; Mattila, Karjaluoto, \& Pento, 2003); the impact of prior experience with similar technologies (Agarwal \& Prasad, 1999; Docampo Rama, 2001; Lu, Yu, \& Liu, 2003) and lack of specific knowledge about computers (Compeau \& Higgins, 1995; Rogers, Meyer, Walker, \& Fisk, 1998; Venkatesh \& Davis, 1996). Umemuro (2004) argue that the attitude of potential users towards the technology also determines its adoption.

Some attitudes among older people have been identified as indicators of a decision to adopt computer use. For example, within the Technology Acceptance Model (Bagozzi, Davis, \& Warshaw, 1992), perceived usefulness (a measure of the subjectively defined benefits of technology use) and perceived ease-of-use (a measure of user's degree of satisfaction with accessibility) have been argued to be a strong determinant of older people's rational intention to use ICTs (Ryu, Kim, \& Lee, 2009). Davis (1989) defined "perceived usefulness" as "the degree to which a person believes that using a particular technology would enhance his or her job performance" and "perceived ease-of-use" as "the degree to which a person believes that using a particular system would be free from effort" (p. 320). In essence, the perceived relevance and benefits of computer use is an important decisional factor among many older people (Melenhorst, Rogers, \& Bouwhuis, 2006; Selwyn, Gorad, Furlong, \& Madden, 2003; Sharit, Czaja, Perdomo, \& Lee, 2004). However, older adults may also have strong emotional reactions, such as fear and "computer anxiety" to using computers. Such reactions could influence their decision making process when they are inexperienced, and negatively affect initial use and adoption (Czaja et al., 2006; Ellis \& Allaire, 1999). Furthermore, older people's computer and internet literacy levels are diverse. As older people are a very heterogeneous group (Neves \& Amaro, 2012; Wagner, Hassanein, \& Head, 2010), the challenges that they experience through computer learning processes are diverse (Wagner, Hassanein, \& Head, 2010) and there is a need to understand the scope of such diversity and how it may affect the adoption of ICTs. For example, many visually impaired older adults are in the position of having to learn how to use adaptive technological devices from scratch before they can explore their potential. The absence of prerequisite technical literacy can exclude them from the benefits of computers and the internet.

While there has been a growing body of work focussing on the barriers to 
internet access for older people over the past decade (Gerber, 2003; Hayhoe, 2011; Murphy, Kuber, McAllister, Strain, \& Yu, 2008; Papadoupoulos \& Goudiras, 2005; Yu, McAlister, \& Dodds, 2004) and a few exploring their experiences (Douglas, Cocoran, \& Pavey, 2007; Fuglenid, 2011), there seems to be paucity of research focussing on older age group with vision impairment. In essence, despite being a group less likely to use the internet, less attention has been paid to capturing their experiences and perceptions, as an approach to understanding how the internet may be of relevance to their day-to-day lives (RNIB, 2013).

Although some studies emphasised that the internet could enable older people with disabilities to live autonomously and cope with challenges of daily living (Comyn, Olsson, \& Guenzier, 2006; Simpson, 2009), to what extent such benefits may be applicable to visually impaired older users remains unknown. Difficulties with making adjustments to functional loss as a result of vision impairment could cause feeling dependent on others or frustrations at having to solicit for assistance (Percival \& Hanson, 2005). A visually impaired person who is unable to make necessary adjustments to adapt or compensate for such losses might go through symptoms such as anxiety, stress, adjustment disorder, and major depression which might ultimately affect their ability to socialise with others (Casten \& Rovner, 2006; Rovner, Casten, Leiby, \& Tasman, 2009). The most common outcome of these processes is a diminished sense of independence and self-esteem.

As older adults with vision impairments require assistive devices to access the internet, they are a group with distinct patterns of internet access. The World Wide Web Consortium (W3C), international community led by Tim Berners-Lee, inventor of the World Wide Web, and supported by a staff of technical experts coordinates web standards based on community consensus (World Wide Web Consortium, 2014). Properly designed websites which conform to guidelines stipulated by W3C, can be used by people with disabilities (World Wide Web Consortium, 2014). However, many sites are designed without adherence to the W3C protocols and guidelines thereby making it difficult or impossible for some people to use them. There is a need to understand how visually impaired older people use the internet and how it fits into their daily lives in order for policies and advances in technology to adopt a functional approach to bridging the digital divide (Kane, 2011; Kane, Bigham, \& Wobbroack, 2012). In considering the paucity of research on the context of internet use among visually impaired older people, the current study explored their experiences and 
perception with a view to highlighting the benefits and the challenges it currently holds for them.

\section{Method}

The sample for this study consisted of 20 respondents, all of whom were members of a voluntary organisation for blind people in Newcastle (North-East of England). The participants were aged between 60 and 92. They consisted of 12 women and eight men. Respondents possessed a wide range of age- related vision impairments and visual condition, varying from partial sight to total blindness. Participants who had Cornea dystrophies were partially sighted while participants with Age Related Macular Degeneration (ARMD), Glaucoma and Retinitis Pigmentosa were totally blind. Participants' experiences with internet use ranged from complete beginners to advanced users. The sample was not intended to be representative of the visually impaired community, but to be contextually sympathetic to the visually impaired students at the centre at the time the research was conducted.

The research framework used in this study is the Qualitative paradigm (Williams, 2007), using an ethnographic approach of mainly interviews and observations. The interviews were topic-guided. This design was adopted in order to be able to explore other topics and questions as they emerged (Phillimore \& Godson, 2004). It is a more suitable method for gaining tacit knowledge of the social context of systems use, and real life interactions and experiences (Bodker, 2006; Seidman, 1998). The approach emphasises the understanding of meaning in context, and that meaning is created through interaction with a conversational partner. The concepts of multiple experiences narrated by different respondents and the importance of contextualising reality based on respondents' experiences are further characteristics of this approach (Moggridge, 2007).

All participants used the screen readers. With permission from participants, interviews were audio recorded. Interviews were conducted with participants over a period of 6 months; and a second interview was scheduled when there was need to build on emerging findings from the first. The repeat interviews were held about 4-6 weeks apart, enabling participants to reflect on what they said. In other words, the second interviews gave a potential for a more reflective interview (Seidman, 1998). Before the commencement of the second interviews, analyses of first interview 
transcripts were verbally reported to participants. This was to ensure that there were no misinterpretations (Polit \& Beck, 2004). This iterative design aimed at generating clearly guided and detailed data from participants (Seidman, 1998). Interviews focused on background information about the participants and their experiences with internet use. The open-ended natures of questions enhanced exploration of narratives (stories) of participants from their experiences and also helped to develop a rapport with them about the meanings they attached to internet use. Pseudonyms have been used to preserve anonymity. Participants' ages and types of vision impairments are presented in parenthesis after quotes. Ethical approval for this study was granted by Northumbria University.

\section{Data analysis}

Interviews were thematically analysed, through the creation and application of "codes" to data from interview transcripts (Strauss \& Corbin, 1998), and following Grounded Theory principles (Glaser \& Strauss, 1967). Audio taped interviews were transcribed and analysed using qualitative data analysis software (Nvivo). The methodological principles of "open and axial coding" were used to draw related patterns from participants' comments (Strauss \& Corbin, 1998). Relevant thematic codes were identified by constant examination of themes and crosschecking of these through referencing to individual transcripts and the collective data set.

\section{Results}

Five themes emerged from the study, namely: Keeping in touch, Barriers to internet use, Maintaining independence and social inclusion, Coping with vision impairment, and Hopes and fears.

\section{Keeping in touch}

Many participants reported that their main motivation for using the internet was to enable them keep in touch with their social networks. They felt that the ability to stay connected to people enhanced their sense of belonging to society and also gave them the opportunity to contribute to the social well-being of others and be active social participants. They reported that using emails enabled them to manage their social engagements with other people in better ways. Some participants who lived alone said that the internet helped them to supplement 
offline interpersonal interactions and reduce the feeling of loneliness and social isolation:

"The contacts keep you going especially in my case because I'm alone. I live on my own. It's not easy for me to see somebody. I use the internet daily. It's marvelous because when I use it, I don't feel so isolated and I don't feel lonely" [Oscar, 82, Glaucoma].

“Well, because I am blind, it's of enormous benefit probably more benefit to me than it would be to sighted people...I would hate if I have to do without it. Without emails, I would never have been in touch with all these people" [Harold, 87, Glaucoma].

"Well, I just like think that the older you get, the more you're likely to desire keeping in touch...I mean when you are younger, you don't bother so much, but when you are older...you think goosh...I suppose you think...l'm not here for that much longer. I would like to contact people I used to know and see how they are and get to know how life is going and everything" [Jennifer, 80, Glaucoma with Complicated cataract].

Many participants regarded email as easier to use for maintaining social contacts than other technologies. They expressed their preference for emails over telephones because they felt that vision impairment made telephone use difficult. The reason often stated was that it was difficult to see the numbers inscribed on the phone buttons and the name of the caller on the screen.

"Visually impaired and blind people usually find telephones difficult to dial a number. I've got one with 5-one push buttons but there's even a problem because I can't sometimes remember who is on what button" [Oscar, 82, Glaucoma].

"I live alone and it's an easier way of socialising for me than telephone. It means I'm not isolated. I feel as if I'm not alone because there is always a thread I can pick up, and there's always someone on that thread to chat with" [Regina, 87, Glaucoma]. 
Similarly, some participants prefer the internet than watching TV because they find the experience more fulfilling in meeting their social goals.

"If it came to a choice between keeping the computer going with the internet connection or keeping the TV going, if it was my choice, I'll dump TV and keep my computer. I wouldn't do without internet connection" [Fred, 65, Age Related Macular Degeneration (ARMD)].

A number of participants in this study reported making new contacts through the Internet forums. Their comments suggested that unlike the physical world where it might be difficult to meet visually impaired people who also shared similar interests, theme based discussions on internet forums allowed them to connect with others.

"I'm always getting new contacts through the forums and there are many clever blokes who are visually impaired on the forum. We share ideas on anything we think may be difficult. Through it, I met a lady. She saw my name on the forum, because I was doing some research going backwards in my family to find out where my grandfather came from. But she saw my name and e-mailed me. I've-mailed her back. She let me go into her family tree. We are friends now" [Alfred, 87, ARMD].

Such social interactions start from understanding collective interests which provide opportunities to discuss subjects that may be difficult to approach in the real world (Lindlif \& Shatzer, 1998). Participants seemed not to feel the constraints of the media lacking visual cues because they had already become used to communicating without visual cues.

\section{Barriers to internet use}

Many participants expressed their frustrations with internet use. They felt that it was fraught with so many challenges that discouraged them from using the internet as much as they would like to.

\section{Internet interface designs}

Although there are guidelines stipulated by the worldwide web consortium on how to make websites accessible to people with disabilities, comments from participants 
suggested that web pages still remained difficult to access for many visually impaired older adults. Their responses indicated that many web lay-outs presented a major barrier to their ability to use the internet. Despite using large fonts, participants in this study criticized distractions on web-pages.

"The internet pages should be made clearer. They've got advertisements everywhere. They've got too much, too busy for visually impaired people because it makes it confusing for us. It's just too fussy" [Sharone, 66, Cornea dystrophy].

"You are bound to go from A to B for some things and then see that you'd go to something else...in fact, sooner or later, you think what I was looking for in the first place because there are lots of things on the way...l just get completely useless...I don't know" [Thelma, 88, Glaucoma].

Many participants regarded some interface designs as not being fair to visually impaired people and criticised them as not being "inclusive designs" because visually impaired people had not been duly considered. In particular, they complained about the website lay-out design of social networking sites. They felt that the lay-out is usually confusing because the fonts were not tailored to support usability by visually impaired people.

"I can't do Facebook, I can't do Twitter because I can't read their screens. If you can't read the screen on Facebook, you don't know where to go" [Alfred, 87, ARMD].

"I tried using Facebook but I can't. I can bring the screen up and make the font as big as possible but it's still difficult to see. There are little things everywhere. I miss the things going on because it's not visible. Sideways you've got all those advertisements" [Sharon, 66, Cornea dystrophy].

One of the participants believed that such design and lay-out of SNS often discouraged visually impaired people from socialising online mainly because the colour schemes did not consider people with colour blindness.

“They don't use the right colours for people who are partially sighted. I feel 
very sorry for people who have colour blindness. The sites must be horrendous for them to use. You know when you've got sight impairment, you can't see, there's a lot of colours you've got to lose. If the backgrounds are on colours, you can't see the writings at all" [Samantha, 64, Cornea dystrophy].

This suggests that the increasing use of social network sites (SNSs) for socialisation among older adults (Madden, 2010) may not be applicable to this group. For many other participants, they believed that because they did not grow up in a technological era, it would be more difficult to learn how to use them in more constraining conditions like being visually impaired. This point was emphasised in one participant's comment when she said:

"I worked in a non-electronic age but seeing what is happening now, it's quite frightening at times as well as the innovations" [Regina, 87, Glaucoma].

On the other hand, lack of interest was a common reason given by other participants who were aware of social network sites but did not use them, as illustrated in the following quote:

"I know about Facebook and tweeting, but a lot of it just seems like a waste of time. I'm sure it's suitable for a lot of people to actually expand their friendship base but at the moment, I have more than enough to cope with" [Vivian, 65, Glaucoma].

Vivian's comments suggested that the indifference of many visually impaired people about social media was not always due to vision impairment or lack of awareness but could also be attributed to apathy towards use of social media because they attached little relevance to it.

\section{Cost of assistive devices and training}

The cost of screen readers was perceived as a barrier to internet access and was a recurrent issue in participants' comments. Many earlier studies have highlighted this particular factor as contributing significantly to the disability divide (Hollier, 2007; Lazar \& Jaeger, 2011; Shaw Trust, 2013). Participants however, noted that they were not advocating for pricing in their favour but for an affordable price that will enhance equality of internet access. 
"I think there needs to be a good look at where equipments and assistive devices can be purchased at a lot more affordable prices for visually impaired people. The costs are outrageous!" [Newton, 68, ARMD].

The issue of cost thus remains a recurring barrier for people with disabilities. Many participants believed that having a universal design could be a strategic approach toward integrating people with disability and also reducing the price. They argued that if the same design were made for everyone, manufacturers could effectively manage the cost of production and control the exorbitant prices of specialist devices for people with vision impairment.

"Every adaptive technology for internet access is expensive...but if they make it accessible to everyone, all that equipment as standard, hopefully, the demand will be so high that the prices will come down and it will benefit visually impaired people" [Vivian,65, Glaucoma ].

“Well, it's expensive...it's just like everything else for blind people...it's terribly expensive...but we could afford that really...I mean my husband says anything that will help you and your eye sight, it's good" [Alice,82,Glaucoma].

There were also concerns about skill acquisition for use of computers. Although training and support could help older people overcome some of their anxieties, enable them to build skills and develop their confidence using the computer, some participants perceived computer training as difficult. In their opinion, the actual difficulty was not only due to vision impairment, but to ageing as well. Kimberly felt that as a visually impaired older person, learning to use the computer has been one of the most challenging tasks for her to overcome because she was not brought up with computers. In her comments:

"If you are visually impaired and a bit older, you haven't been brought up with computers; I think it's like climbing the heavenly hills to me [chuckles]...although I am desperate to learn, I think it's a struggle. I leave the centre on Tuesdays utterly exhausted" [Kimberly, 69, ARMD].

While these barriers continue to hinder equitable internet access to the blind 
and partially sighted, those who can afford assistive devices also face many challenges. The next section describes in details report of participants' experiences of internet use has not been too helpful for them to feel socially integrated.

\section{Maintaining independence and social inclusion}

The role of the internet and ICT in general in enhancing their social inclusion and participation in today's dynamic ICT world was perceived as crucial by many participants. However this comment was commonly mentioned by participants aged between 60 and 70 years. They believed that they were unable to participate as fully as sighted people did in the current advancing ICT age. Issues raised included the ease of use of the internet to perform daily tasks, such as paying their bills online, banking and shopping. These are discussed in-details below:

\section{Reading bills online}

While internet facilities help many users to make online payments and afford them many more advantages due to the convenience, such benefits elude many people with vision impairment because they do not have the same internet access as sighted users. For example, a participant complained of not being able to read her bills despite using a screen reader:

"You see, it can get so frustrating on simple things like checking the council tax paid up to date. Checking what your gas bills have been or able to backtrack over departments of works and pension. Unless you have problems with your vision, I can't tell you how frustrating it is discussing some of these" [Kimberly, 69, ARMD].

Due to limited mobility and sight impairment, many participants said they found it difficult to carry out such activities independently. They reported that they depended largely on family or friends. Many participants said that depending on other people diminished their self-esteem and sense of independence. Their responses suggested that internet shopping was fraught with many difficulties despite using a screen reader.

"I used to live with my daughter and son-in-law and she used to do the shopping for me...but now, I am on my own because I now live alone. I would 
love to learn to do internet shopping. It's important that I'm able to do it without much difficulty...that will be an excellent thing. 'I would like to do the shopping on the internet but I can't because their design is bad. Recently, I have had a volunteer from here who's been going shopping with me for grocery you know. It's nice to have somebody with me who can help me" [Regina, 87, Glaucoma].

"It's difficult to learn and use a screen reader for shopping the number of times you have to press the buttons and listen to audio instructions to get to the place you want to get to is so tedious. I think it's the design of the web pages themselves. Even though there is something called accessibility options, it still doesn't make life easy for the person without sight to learn how to navigate" [Kevin, 87, Retinitis Pigmentosa].

These comments suggested that some participants recognised the central role of computers in their daily lives and its potential to make them do things conveniently; unfortunately they felt that they were not getting the best they could get from computer use. Access to carry out their day-to-day activities remained limited. They believed that this might hinder their chances of being fully integrated into society.

Some participants who got assistance from their family or friends to the supermarket believed that it gave them opportunities to meet people and to socialise. However, they voiced concerns that the rise in online shopping might lead to more segregation of visually impaired people and other people with disability because they did not have the same internet access as sighted people. Many of the participants made comments suggesting that, while they could accept giving up certain luxuries such as driving a car or gardening, they did not want to compromise their independence:

"I don't travel but I travel all the time with my brother and I suppose I rely on him and because I can't see, I mean like when I look at you now, I cannot see you there at all because this eyes is completely blind and l've got peripheral vision in this one, so, when you are outside, I find it difficult, well I suppose the first thing you think of is I'm I gonna trip on anything, if there's a small ball or if it's uneven, you think you can easily fall...and you think when you are older, 
all these brick and when you go to the station, you cannot read any of the boards or anything. Now if I lost my husband which heaven forbid...he's a gem really...but if anything happen to him, I would try and get around on my own and I just have to go and ask somebody and say 'excuse me I'm registered blind, would you mind reading this for me? I would give computer use a try because I'm quite determined to learn it" [Amanda, 78, ARMD].

Similarly, Wendy commented on sharing support with others at the computer classes and learning alternative ways to enhance independence through computer use:

"In fact, it's something I would never had thought of doing if it hadn't been suggested to me and I thought I'll never do that...and of course I came to the classes and I think it's wonderful because just as I say, you are socialising...it's one of those things, finding something out about others at the centre and doing something to help them" [Wendy, 89, Glaucoma].

\section{Coping with vision impairment}

Many participants described how they used internet to compensate for their sight impairment, such as difficulties with reading, writing or in some cases, compensating for relinquished activities of interest. From participants' views, writing guides may not be sufficient to make writing easier. Keeping social contacts through hand written mail was described as nearly impossible without vision. In addition to poor hand writing and inability to see what they were writing, they also cited many other difficulties such as inability to go to the post-office due to limited mobility. Kimberly, complained about having bad hand-writing, and cited this shortcoming as her primary motivation for her interest to learn to use emails:

"I need a computer now because my handwriting is bad" [Kimberly, 69, ARMD].

Many participants had given up some activities they enjoyed doing as a hobby because of vision impairment. Previous studies suggest that relinquishing valued activities is associated with increased risk of cognitive decline and depression in older adults with vision impairment (Casten \& Rovner, 2006; Rovner et al., 2009). 
Findings suggested that many participants were able to successfully find a substitute for lost hobbies in computer use and were successfully adjusting to such losses via internet use. This is illustrated in Rosaline's comment:

"Using the computer is now one of my main leisure activities because I used to do a lot of knitting and sowing and reading and things like that. Well...I can't anymore. I have talking books and I have got a CCTV reader but I have to give up most of my hobbies. I can't do gardening anymore. I used to spend a lot of time in the garden but l'm getting restricted now to talking books and the computer. So it's really becoming a bigger part of my life" [Rosaline, 78, Retinitis Pigmentosa].

While many participants gave up on their hobbies or found a new hobby in internet use, others simply sustained their interest for a lost hobby by engaging in related discussions online.

"I suppose using the internet, you get into the bigger world where a lot of people who are visually impaired are stuck in the house so if you've got a computer, it does open a whole new world to you and you can talk about your interests online with others who share the same interest" [Abigail, 61, Cornea dystrophy].

\section{Hopes and fears}

Many comments by participants reflected their fears about being excluded from participating in rapidly advancing ICT world. Typically, such comments portrayed apprehension that as many technological devices take haptic forms (touch screens), it could potentially make a bad situation worse. Hence, they expressed so much concern that such innovation might marginalise them from the potential benefits of internet use. The following quotes illustrated apprehension in their responses:

"You just got that touch screen things now...so my concern is if it all goes to touch things, l've got arthritis in my hands and I find it hard to do the touch thing. You all happen to forget those who have difficulty in using hands/palms, how would that relate to those palms with hands that don't always...it took me an hour to get that up. As I couldn't feel the touch because as you get older 
they feeling is not as good but I find that very difficult" [Samantha, 64, Cornea dystrophy].

Finally, as it is often argued that the speedy rate of advancement in ICT innovation and web-designs render accumulated knowledge and skills of older people redundant thereby contributing to their relegation to obsolete technologies (Simpson, 2009). The progress being experienced by sighted users as technology undergoes constant modification and improvement may not necessarily be regarded as progress for this group. Some of the participants had suggestions for the technologies they would like to see developed in the future in order to enhance not just their access, but guarantee easy access for every user without discrimination on disability:

"I think apple one of their selling point is that the accessibility is built in ...it's not just there for blind people...it's there for everybody...so hopefully their prices will come down actually. In my opinion, the easiest thing for visually impaired people on internet use and other ICT would be voice recognition. The modern day technology with difficult access to visually impaired people isn't really improving our lives and lots of technology is making it much more difficult" [Vivian, 65, Glaucoma].

These findings reveal that whilst computing technologies continue to advance rapidly, many visually impaired older adults struggle to catch up. Participants nursed fears of being left behind and of not fully benefiting from the internet.

\section{Discussion}

This study suggests that visually impaired older people believe that they can manage their daily tasks better through internet use. Many of them successfully used online socialisation processes to keep in touch with family and friends. Physical meetings with others can be difficult due to the challenges of mobility and identifying people. They believed that online environments provided exciting virtual platforms to socialise, and seek vital information from others in a similar situation. Another perceived usefulness of online forums was that it afforded them opportunities to share their interests with others. In essence, considering the difficulty in connecting 
with people of similar condition offline, the online environment was perceived as a platform that supported such levels of connectivity and enabled mutual sharing of life events and social support.

Although internet use helped visually impaired older adults in this study to make needed adjustments and to cope with functional losses associated with vision impairment (such as losses relating to leisure activities, reading and writing), they however, did not achieve such feat without struggle. While participants were eager to use the internet to make life easier, their awareness about the difficulties surrounding access made them apprehensive about how they could participate in society. The implication is that inequity in internet access remains a hindrance to social integration of this user group particularly as the internet revolution is currently taking many social activities into online media. The issue of cost as a barrier to internet uptake by visually impaired people seem to be a recurrent problem contributing to the digital divide. There is a real danger that such socially constructed inhibiting factors may leave visually impaired older people further disadvantaged and less capable of using the internet (Krishna \& Panchanathan, 2010). The ability to perform instrumental activities of daily living such as shopping, paying their bills online and communicating with others, were interpreted by participants as integral to their sense of integration into society. Thus, the themes demonstrated aspect of the lives of visually impaired older adults that they perceived internet use was invaluable.

Drawing on the experiences of participants in this study, findings support previously reported findings from studies on older people and computer use that, the internet can enable older people to maintain existing social relationships, expand their social networks and facilitate communication with others (Bargh \& McKenna, 2004; Ellison, Steinfield, \& Lampe, 2007; Godfrey \& Johnson, 2009; Pfeil, Zaphiris, \& Wilson, 2009; Sayago \& Blat, 2010; Xie, 2007). Nevertheless, findings emphasized that the increasing technological complexity seems to be adding more difficulties to internet access for this group. Such difficulties reported by participants in this study included complex website interface designs that did not consider their vision needs, increasing cost of some assistive device such as screen readers, inadequate training, and lack of inclusive designs in technology development. From experiences of visually impaired older people, the complexity of internet use as technological advancements progress rapidly presents an enormous challenge. In the disappearance of simpler, more self-explanatory systems, adequate training and 
support is constantly needed for this group.

\section{Implications of findings}

Although many free screen readers exist, they are not effective for all users or on all websites. Thus, the removal of more traditionally disabling barriers such as the prohibitive cost of screen readers, and provision of adequate training and awareness on appropriate screen readers would be an important strategic approach to tackling the burden of the digital divide. There is a need for policy geared at bridging the digital divide to focus on enhancing web accessibility and promoting availability of affordable assistive devices for internet access. As emphasised in this study, poor access to online services in the light of rapid technological advancement further complicates the digital divide and social exclusion of people with vision impairment.

The findings also emphasize the existence of a continuum in the development and adoption of technologies. At one end of the continuum, for instance, is the creation of ICT facilities that can be used by visually impaired people and people with other forms of disabilities to cope with functional loss and overcome the challenges they face with daily living. At the other end of the continuum is the fundamental question about social dimensions of technology design, diverse criteria for instrumentation that must function in diverse characteristics of disabilities, and creation of effective policies that are essentials to the promotion of values-sensitive adaptive technologies (Bilbao-Osorio, Soumitra, \& Lan, 2014; Sandler, 2012). For example, it is important to understand the different needs of people with different types of vision impairment in creation of ICT facilities for them. There are debates that the development and adoption of assistive technologies will be associated with public view of ageing and disability as problematic. Many of such arguments point out that, such adaptive device could automatically define disability and may compound stigmatisation of disability because their designs are not universal and integrative (Gaffney, 2010). In considering such arguments, it might be important that ICT developers begin to explore inclusive technologies.

Findings from this study have implications not only for ICT practitioners, but also professionals in ocular rehabilitation. It is hoped that they can contribute to knowledge on the social context of internet use among visually impaired older persons so that awareness on sustaining independent living through use of CMC after sight loss could be further promoted. The understanding created by this study 
to expose the domains of internet use for activities of daily living and complexities surrounding internet access for this group will help channel concerted efforts in bridging the digital divide.

The current study has several limitations which can be overcome in future research. Firstly, the study did not explore how the different types of vision impairment could have played a role in participants' ability to use the internet. It is possible that the different kinds of vision impairment or the severity of vision impairment might have influenced how participants respond to dynamics of internet use, what daily tasks they prioritise, their coping skills and their perceptions of the usefulness of the internet. The qualitative nature of the study makes it impossible to generalise findings from the current study to other visually impaired older internet users.

\section{Conclusion}

In summary, the themes specifically reveal aspects of their social needs which they considered as goals that could be met via internet use. Findings suggested that the internet could be a potentially enabling tool for visually impaired older people to cope with challenges posed by vision impairment and to maintain their independence. In particular, it afforded participants opportunities to maintain social contacts and perform daily tasks in ways that would be otherwise difficult in physical world due to vision impairment. However, while the benefits of use of the Internet for older people with vision impairment seem to be consistent with reported benefits among their sighted peers, the difficulties caused by vision impairment seem to be more than the reported difficulties among their sighted peers. The challenges and opportunities of internet use for this group, together with the global ICT revolution pose fundamental considerations about inclusive design.

\section{References}

Agarwal, R., \& Prasad, J. A. (1999). Are individual differences germane to the acceptance of new information technologies? Decision Sciences, 30(2), 361391.

Age UK. (2013). North-South divide for older people's internet usage. Retrieved from http://www.ageuk.org.uk/latest-press/archive/internet-use-amongst-olderpeople-subject-to-northsouth-divide/ 
Bagozzi, R. P., Davis, F. D., \& Warshaw, P. R. (1992). Development and test of a theory of technological learning and usage. Human Relations, 45(7), 660-686.

Bargh, K. A., \& Mckenna, K. Y. A. (2004). The internet and social life. Annual Review of Psychology, 55(1), 573-590.

Bilbao-Osorio, B., Soumitra, D., \& Lan, B. (2014). The global information technology report 2014: Rewards and risks of big data. Geneva, Switzerland: World Economic Forum.

Bishop, J. M., Taylor, L., \& Froy, F. (2000). Computer-mediated communication use by the deaf and hard-of-hearing. Kybernetes, 29(9), 1078-1086.

Bodker, S. (2006). When second wave $\mathrm{HCl}$ meets third wave challenges. In: Proceedings of the NordiCHI, Olso (Norway), 1-7.

Casten, R. J., \& Rovner, B. W. (2006). Vision loss and depression in the elderly. $\begin{array}{llll}\text { Psychiatric } \quad \text { 23(13). Rimes, from } & \text { Retrieved }\end{array}$ http://www.psychiatrictimes.com/display/article/10168/52151

Compeau, D., \& Higgins, C. A. (1995). Application of social cognitive theory to training for computer skills. Information Systems Research, 6(2), 118-143.

Comyn, G., Olsson, S., \& Guenzier, R. (2006). User needs in ICT Research for Independent living, with a focus on health aspects. Report on a joint DG JRC/IPTS-DG INFO Workshop held in Brussels, 24-25 November, 2005.

Cook, G., Klein, B., Cader, R., Moyle, W., Maris, S., Clarke, C., \& Reed, J. (2010). Potential technological solution to promote well-being in older age. Generations Review 20(3). Retrieved from http://www.research.ed.ac.uk/portal/files/12472125/Potential technological solutions to promote mental well being in older age.pdf

Czaja, S. J., Charness, N., Fisk, A.D., Hertzog, C., Nair, S. N., \& Rogers, W. A. (2006). Factors predicting the use of technology: Findings from the Center for Research and Education on Aging and Technology Enhancement (CREATE). Psychology and Aging, 21(2), 333-352.

Davis, F. D. (1989). Perceived usefulness, perceived ease of use, and user acceptance of information technology. Management Information Science Quarterly, 13(3), 319-340.

Docampo Rama, M. (2001) Technology generations handling complex user interfaces. PhD Thesis. Eindhoven: Technische Universiteit Eindhoven.

Douglas, G., Cocoran, C., \& Pavey, S. (2007). The role of the WHO ICF as a framework to interpret barriers and inclusion. British Journal of Visual Impairment, 25(1), 32-50.

Eastman, J. K., \& lyer, R. (2004). The elderly's uses and attitudes towards the Internet. Journal of Consumer Marketing, 21(3), 208-220.

Egan, J., Chenoweth, I., \& McAuliffe, D. (2006). Email-facilitated qualitative interviews with traumatic brain injury survivors: A new and accessible method. Brain Injury, 20(12), 1283-1294.

Ellis, E. R., \& Allaire, A. J. (1999). Modelling computer interest in older adults: The role of age, education, computer knowledge, and computer anxiety. Human Factors, 41(3), 345-355.

Ellison, N. B., Steinfield, C., \& Lampe, C. (2007). The benefits of Facebook "friends": Social capital and college students use of online social network sites. Journal of Computer Mediated Communication, 12(4), 1143-1168. 
European Commission. (2007). European i2010 initiative on e-inclusion. To be part of the information society. Retrieved from http://ec.europa.eu/governance/impact/ia carried out/docs/ia 2007/sec 2007 1469 en.pdf

Eysenbach, G. (2008). The impact of the internet on cancer outcomes. $A$ cancer Journal for Clinicians, 53(6), 563-371.

Fuglenid, S. K. (2011). The barriers of use of ICT for people with visual impairment. UACHI Proceedings, 1(10), 452-462.

Gaffney, C. (2010). An exploration of the stigma associated with the use of assistive devices. Journal of Sociology, 3(1), 67-78.

Gerber, E., \& Corinne, K. (2001). Who is surfing? Internet access and computer use by visually impaired youths and adults. Journal of Visual Impairment and Blindness, 95(3), 176-181.

Gerber, E. (2003). The benefits and barriers to computer use for individuals who are visually impaired. Journal of Visual Impairment \& Blindness, 97(9), 536-550.

Glaser, B. G., \& Strauss, A. L. (1967). The discovery of grounded theory. Strategies for qualitative research. New York: Aldine Publishing Company.

Godfrey, M., \& Johnson, O. (2009). Digital circles of support: Meeting the information needs of older people. Computers in Human Behavior, 25(3), 633-642.

Hageboom, D. L., McDermott, R. J., Perrin, K. M., Osman, H., \& Bell-Ellison, B. A. (2010). Internet use and social networking among middle age and older adults. Educational Gerontology, 36(2), 93-111.

Hayhoe, S. (2011). Web design, internet use and visual impairment. In BETT 2011: 12-15. January Olympia, London, UK.

Hollier, E. S. (2007). The disability divide: A study into the impact of computing and internet-related technologies on people who are blind or visually impaired. GLADNET collection paper 340. Retrieved from http://digitalcommons.ilr.cornell.edu/gladnetcollect/340/

Juznic, P., Blazic, M., Mercun, T., \& Plestenjak, B. (2006). Who says that old dogs cannot learn new tricks? A survey of internet/web usage among seniors. New Library World, 107(7), 332-345.

Kane, S. K. (2011). Usable gestures for blind people: Understanding preferences and performance. Proceedings of the SIGCHI Conference on Human Factors in Computing Systems, 412-423. New York, USA.

Kane, S. K., Bigham, J. P., \& Wobbrock, J. (2012). Fully accessible touch screens for the blind and visually impaired. Retrieved from http://www.academia.edu/3449393/FULLY ACCESSIBLE TOUCH SCREEN S FOR THE BLIND AND VISUALLY IMPAIRED

Krishna, S., \& Panchanathan, S. (2010). Assistive technologies as effective mediators in interpersonal social interactions for persons with visual disability. ICCHP ' 10 Proceedings of the $12^{\text {th }}$ International Conference on Computers helping people with special needs (pp. 316-323).

Lazar, J., \& Jaeger, P. (2011). Reducing barriers to online access for people with disabilities. Issues in Science and Technology, 27(2), Retrieved from http://issues.org/27-2/lazar/

Lindlif, T. R., \& Shatzer, M. J. (1998). Media ethnography in virtual space: Strategies, limits, and possibilities. Journal of Broadcasting \& Electronic Media, 42(2), 170-90.

Lu, J., Yu, C. S., \& Liu, C. (2003). Technology acceptance model for wireless Internet. Electronic Networking Applications and Policy, 13(3), 206-222. 
Madden, M. (2010). Pew internet and American life project. Retrieved from http://www.pewinternet.org/2010/08/27/older-adults-and-social-media/

Mattila, M., Karjaluoto, H., \& Pento, T. (2003). Internet banking adoption among mature customers: Early majority or laggards? Journal of Services Marketing, 17(5), 514-528.

Melenhorst, A., Rogers, W., \& Bouwhuis, D. (2006). Older adults' motivated choice for technological innovation: Evidence for benefit-driven selectivity. Psychology and Aging, 12(1), 190-195.

Moggridge, B. (2007). Designing interactions. Massachusetts: The MIT Press.

Murphy, E., Kuber, R., McAllister, G., Strain, P., \& Yu, W. (2008). A empirical investigation into the difficulties experienced by visually impaired internet users. Universal Access in the Information Society, 17(7), 79-91.

Neves, B. B., \& Amaro, F. (2012). Too old for technology? How the elderly of Lisbon use and perceive ICT. The Journal of Community Informatics, 8(1), 1-20.

Niehaves, B., \& Plattfault, R. (2014). Internet adoption by the elderly: employing IS technology acceptance theories for understanding the age-related digital divide. European Journal of Information Systems, 23(6), 708-726. doi: 10.1057/ejis.2013.19

Office of National Statistics. (2013). Report: Over 7 million adults in the UK have NEVER used the internet, with a third of elderly people missing out. Retrieved from http://www.dailymail.co.uk/sciencetech/article-2392980/Over-7-millionadults-UK-used-internet-elderly-people-missing-out.html.

Papadopoulos, S. K., \& Goudiras, D. B. (2005). Accessibility assistance for visually impaired people in digital texts. British Journal of Vision Impairment, 23(2), 75-83.

Percival, J., \& Hanson, J. (2005). I'm like a tree a million miles from the water's edge': Social care and inclusion of older people with visual impairment. British Journal of Social Work, 35(2), 189-205.

Pfeil, U., Zaphiris, P., \& Wilson, S. (2009). Older adults' perceptions and experiences of online social support. Interacting with Computers, 21(3), 159-172.

Phillimore, J., \& Goodson, L. (2004). Qualitative research approach. Indo-Pacific Journal of Phenomenology, 9(2), 1-12.

Polit, D. F., \& Beck, C. T. (2004). Nursing research. Principles and methods $\left(7^{\text {th }}\right.$ ed.). Philadelphia: Lippincott Williams and Wilkins.

RNIB. (2013). Tackling digital exclusion. Older blind and partially sighted people and the internet. Royal National Institute for the Blind. Retrieved from http://www.rnib.org.uk/sites/default/files/digital exclusion report accessible. pdf

Rogers, W. A., Meyer, B., Walker, N., \& Fisk, A. D. (1998). Functional limitations to daily living tasks in the aged: A focus group analysis. Human Factors, 40(1), 111-125.

Rovner, B. W., Casten, R. J., Leiby, B. E., \& Tasman, W. S. (2009). Activity loss is associated with cognitive decline in age-related Macular degeneration. Alzheimer and Dementia, 5(2009), 12-17.

Russell, C., Campbell, A., \& Hughes, I. (2008). Ageing, social capital and the internet: findings from an exploratory study of Australian silver suffers. Australian Journal on Aging, 27(2), 78-82.

Ryu, M., Kim, S., \& Lee, E. (2009). Understanding the factors affecting online elderly user's participation in video UCC services. Journal of Computers in Human Behaviour, 25(3), 619-632. 
Sandler, R. L. (2012). Value sensitive design and nanotechnology. In D. Scott \& B. Francis (Eds.), Debating science; deliberation, values and the common good (pp. 205-225). Amherst, NY: Humanities Books.

Sayago, S., \& Blat, J. (2010). Telling the story of older people e-mailing. International Journal of Human Computer Studies, 68(1), 105-120.

Sayago, S., Sloan, D., \& Blat, J. (2013). Everyday use of computer-mediated communication tools and its evolution over time: an ethnographical study with older people. Interacting with Computers, 23(5), 543-554.

Seidman, I. (1998). Interviewing as qualitative research. New York: Teacher's College Press.

Selwyn, N., Gorard, S., Furlong, J., \& Madden, L. (2003). The information aged: Older adults' use of information and communications technology in everyday life. Ageing and Society, 23(5), 561-582.

Sharit, J., Czaja, S. J., Perdomo, D., \& Lee, C. C. (2004). A cost - benefit analysis methodology for assessing product adoption by older user populations. Applied Ergonomics, 35(2), 81-92.

Shaw Trust. (2013). Can 'digital by default' be accessible? Retrieved from http://webacc.shaw-trust.org.uk/blog/can-\%27digital-by-default\%27-beaccessible/

Simpson, J. (2009). Inclusive information and communication technologies for people with disabilities. Disability Studies Quarterly, 29(1). Retrieved from http://dsq-sds.org/article/view/167/167

Strauss, A., \& Corbin, J. (1998). Basics of qualitative research. Techniques and procedures for developing grounded theory. London: Sage.

Sum, S., Mark, M., Pourghason, M., \& Hughes, I. (2009). Internet use as a predictor of sense of community in older people. Cyberpsychology and Behavior, 12(2), 235-239.

Swindell, R. (2002). Technology and the over 65s? Get a life. Social Alternatives, 20, 17-23.

Umemuro, H. (2004). Computer attitude, cognitive abilities, and technology among older Japanese adults. Gerontology, 3(2), 64-76.

Venkatesh, V., \& Davis, F. D. (1996). A model of the antecedents of perceived ease of use: Development and test. Decision Sciences, 27(3), 451-481.

Wagner, N., Hassanein, K., \& Head, M. (2010). Computer use by older adults: A multi-disciplinary review. Computers in Human Behavior, 26(1), 870-882.

Williams, C. (2007). Research methods. Journal of Business and Economics, 5(3), 65-72.

World Wide Web Consortium. (2014). Web design and applications. Retrieved from www.w3.org/standards/webdesign/

Xie, B. (2007). Using the internet for offline relationship formation. Social Science Computer review, 25(3), 396-404.

Yu, W., McAliister, G., \& Dodds, G. (2004). Multimodal interfaces for visually impaired people to access internet. Retrieved from http://citeseerx.ist.psu.edu/viewdoc/summary?doi=10.1.1.100.2131

\section{Biographical notes}

Patrick Emeka Okonji, OD,MPH, MRSPH, is a PhD candidate in the School of 
Community health at the University of Northumbria, UK. He has worked as an Optometrist and as a Public health administrator for over five years in Nigeria. He is currently a volunteer at the Newcastle Society of Blind People and a Mentor to many students in Public health at Northumbria University. His primary areas of interest encompass digital inequalities and health disparities with a focus on health promotion. He aspires to have a career in academia and develop health care interventions that can inform public health initiatives in developing countries.

Monique Lhussier, HND, PhD, is a research associate/ lecturer at the Community Health and Education Studies (CHESs), Northumbria University Research Centre since 2001. During these, she participated in a variety of research projects articulated, in a first instance, around the needs of people with long-term conditions and the services they receive. She has developed a particular interest and level of expertise in quality of life measurement and conceptualisation. Her doctorate was on the quality of life of people with enduring health needs. It highlighted different paradigmatic positions on quality of life, and used a deconstructive analysis of the dual oppositions underpinning the concept. It also incorporated and highlighted cultural and political understanding of quality of life, through the deconstructive analysis of cultural artefacts and policy documentation.

Catherine Bailey, RGN, BA, PhD, is a research fellow at Northumbria University. Her area of specialism are on Health technologies and older adults; Social aspects of falls and older adults; Lifespace, place and identity; Intergenerational understanding of health and well-being; Ethnography/qualitative, Participatory and deliberative research with older adults; EmeCultural appropriateness of telehealthcare staff training and development: She also has experience in International, rural perspectives; using cultural capital to address social and spatial ageism across the generations; Role of assistive technologies in sheltered housing; International comparison of adoption of home based care technologies and their impact on independent living and quality of life.

Mima Cattan, BSC, MSc, PhD, is a Professor of Public health (knowledge translation). Her area of interest is older people, health promotion, mental health and well-being; evidence based health promotion. Mima was appointed Professor in Public Health at Northumbria University in 2009, and was previously a Reader in 
Health Promotion and Co-Director of the Centre for Health Promotion Research at Leeds Metropolitan University. Mima's research interests include the promotion of mental health and wellbeing in older people, and the development of health promotion interventions to alleviate social isolation and loneliness in later life. Her published $\mathrm{PhD}$ thesis, Preventing social isolation and loneliness among older people: a systematic review of health promotion interventions, has greatly influenced the work of the Campaign. 